\title{
Impact response of various concretes at 2.8-second drop shaft
}

\author{
Radoslav Sovják ${ }^{1,{ }^{*}}$, Josef Fládr ${ }^{2}$, Jiřr Št’ástka $^{3}$, and Michal Frydrýn ${ }^{4}$ \\ ${ }^{1}$ Experimental Centre, Faculty of Civil Engineering, Czech Technical University in Prague, \\ Thákurova 7, 16629 Prague, Czech Republic \\ ${ }^{2}$ Department of Concrete and Masonry Structures, Faculty of Civil Engineering, Czech Technical \\ University in Prague, Thákurova 7, 16629 Prague, Czech Republic \\ ${ }^{3}$ Centre of Experimental Geotechnics, Faculty of Civil Engineering, Czech Technical University in \\ Prague, Thákurova 7, 16629 Prague, Czech Republic \\ ${ }^{4}$ Department of Forensic Experts in Transportation, Faculty of Transportation Sciences, Czech \\ Technical University in Prague, Horská 3, 12803 Prague 2, Czech Republic
}

\begin{abstract}
This paper presents experimental testing of various types of concrete under impact loading by using a 2.8 -second drop shaft. The drop shaft is located in the Josef Underground Laboratory and allows dropping a projectile from 40 meters that results in a maximal velocity of $100 \mathrm{~km} / \mathrm{h}$. Three basic types of concrete were used in the framework of this study. This was normal strength concrete, fibre-reinforced concrete, and highperformance fibre-reinforced concrete. The slabs were constructed $1700 \mathrm{~mm} \times 500 \mathrm{~mm} \times$ $70 \mathrm{~mm}$ in size and the clear span of the impacted slab was $1500 \mathrm{~mm}$. Damage of the slab was recorded and the velocity of the projectile was measured with the high-speed camera before and after the impact. It was demonstrated that high-performance fibre-reinforced concrete has a higher ability to absorb and dissipate the kinetic energy of the impact that their lower strength counterparts.
\end{abstract}

\section{Introduction}

Concrete is the most widely used building material in the world and is often used for various fortifications. Current research in concrete and concrete structures resulted in the development of high-performance fibre-reinforced concrete (HPFRC) with enhanced strength and toughness, which benefits mainly from the fibre reinforcement. This is particularly advantageous in case of elevated strain rate loading. Elevated strain rate loading is very fast and results in extensive damage because most of the energy is dissipated for the fracture rather than for the deformation of the loaded element. Previous research on the dynamic testing of high-performance fibre-reinforced concrete and foam concrete is described in $[5,6,7,8]$.

Two different loading rates are compared in this study. The first is quasi-static loading and the second is impact loading. The strain rate for quasi-static loading is usually around $10^{-6} \mathrm{~s}^{-1}$ and the strain rate for impact loading is usually around $10^{2} \mathrm{~s}^{-1}[1]$. It is hypothesized that in

\footnotetext{
*Corresponding author: $\underline{\text { sovjak@fsv.cvut.cz }}$
} 
the case of cementitious composites with dispersed reinforcement, the damage can stay more localized and thus not propagate furthermore into the structure.

\section{Materials and methods}

Three basic types of concrete were used in the framework of this study. Conventionally used concrete was characterised by the standard amount of cement and the usual compressive strength typically achieved for normal strength concrete. Fibre-reinforced concrete was specified by addition of steel macro fibres $30 \mathrm{~mm}$ in length that resulted in enhanced ductility. High-performance fibre-reinforced concrete was used because many authors suggest that HPFRC with dispersed fibre reinforcement have a much higher ability to absorb and dissipate the kinetic energy of the impact [2-3]. HPFRC has improved compressive strength and performs strain hardening behaviour in tension. HPFRC was constructed by using fibres both $13 \mathrm{~mm}$ and $30 \mathrm{~mm}$ in length (Table 1).

Composition of individual mixtures are provided in Table 1. Basic mechanical properties such as compressive strength and modulus of rupture were investigated on cubes $150 \mathrm{~mm}$ in size and on prisms $100 \mathrm{~mm} \times 100 \mathrm{~mm} \times 400 \mathrm{~mm}$ in size in four-point bending configuration, respectively.

Table 1. Composition relative to cement and mechanical properties of the resulting mixtures.

\begin{tabular}{|l|c|c|c|}
\hline & NSC & FRC & HPFRC \\
\hline Cement & 1 & 1 & 1 \\
\hline Silica fume & 0 & 0 & 0.12 \\
\hline Water & 0.35 & 0.35 & 0.27 \\
\hline Aggregate & 4.8 & 3.53 & 2.52 \\
\hline HRWR & 0.01 & 0.01 & 0.04 \\
\hline Fibres $13 \mathrm{~mm} / 30 \mathrm{~mm}$ & $0 / 0$ & $0 / 0.12$ & $0.09 / 0.09$ \\
\hline \multicolumn{3}{|l|}{} \\
\hline Compressive strength $(\mathrm{MPa})$ & 74.7 & 73.5 & 154.2 \\
\hline Modulus of rupture $(\mathrm{MPa})$ & 6.2 & 6.1 & 13.0 \\
\hline Bulk density $\left(\mathrm{kg} / \mathrm{m}^{3}\right)$ & 2382 & 2382 & 2651 \\
\hline
\end{tabular}

Impact resistance was tested in a 2.8-second drop shaft, which is in the Josef Underground Laboratory [4] and allows dropping a projectile with a mass of $95.4 \mathrm{~kg}$ from the height of 40 meters. This results in the impact energy $36806 \mathrm{~J}$. The projectile used in this study had a quasi-hemispherical nose made of two steel plates welded to the top of the steel cylinder (Fig. 1). The diameter of the projectile was $150 \mathrm{~mm}$ and the impact velocities were around 100 $\mathrm{km} / \mathrm{h}(27.8 \mathrm{~m} / \mathrm{s})$.
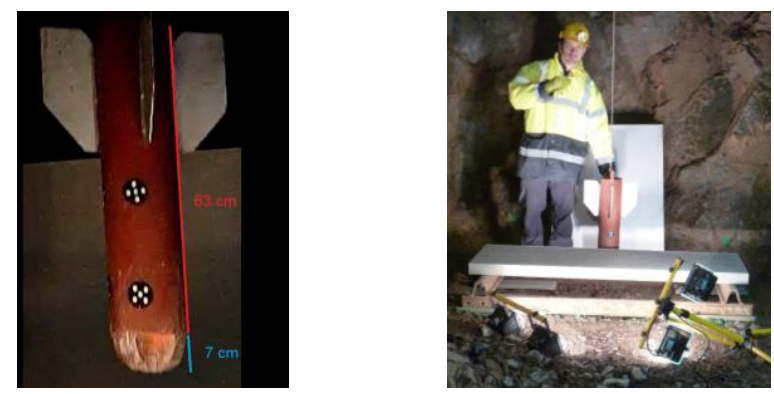

Fig. 1. Details of the $95.4 \mathrm{~kg}$ projectile and its positioning on the slab before the test. 
The slabs were $1700 \mathrm{~mm}$ in length and the clear span was $1500 \mathrm{~mm}$. The width of the slab was $500 \mathrm{~mm}$ and the thickness of the slab was $70 \mathrm{~mm}$. The impact process was recorded with two high-speed cameras with sampling frequencies $600 \mathrm{fps}$ and $4000 \mathrm{fps}$. The projectile was unstrung from the top of the shaft by using a flame to rupture the cable. The flame was used to keep the projectile stable when rupturing the rope. The projectile was falling freely and hit the centre of the slab at the bottom of the shaft with a velocity close to $100 \mathrm{~km} / \mathrm{h}$. Two samples for impact were tested for each mixture.

Besides, static loading was performed on slabs with comparable loading configuration. Herein, a point loading was applied in the centre of the slab and load-deflection diagrams were determined (Fig. 2). The deflection was measured in the mid-span on the sides of the slab. The clear span was $1500 \mathrm{~mm}$ and the support reactions were constant along the width of the slab, according to the supports provided under the projectile impact.

The plates cracked as is typical for bending under quasi-static loading with one or more cracks for NSC, FRC and HPFRC, respectively, which formed at the bottom surface of the plate. Configuration of the bending experiment and load-deflection diagrams of various concrete under quasi-static loading are shown in Fig. 2. Here, the deflection is plotted as an average from both sides' measurements of the slab at the mid-span of the specimen. The graph shows a significantly higher ductility and stiffness of the HPFRC bent element than its FRC and NSC counterparts. The NSC performed quasi-brittle behaviour. The NSC plate failed right after the crack occurred.
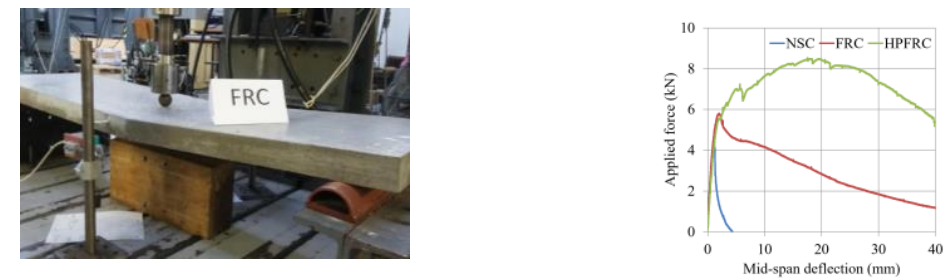

Fig. 2. Quasi-static loading of the slab and its load-deflection response.

\section{Discussion of results}

Regarding the projectile impact, the penetration of the projectile through the slab is shown in two $3 \mathrm{~ms}$ steps for individual concretes (Fig. 3). The crack pattern of the NSC, FRC and HPFRC slabs is shown in Fig. 4. Normal strength concrete is a quasi-brittle material, and this resulted in many cracks that divided the slab into many pieces. Fewer cracks and fewer fragments were found in the case of FRC, which is probably the consequence of an increased ductility and so enhanced flexural toughness of the material. The best performance was achieved in the case of HPFRC which performed the highest flexural toughness, compressive strength and resulted in the least cracks between the tested concretes. Improved behaviour benefits mainly from the fine microstructure and dispersed fibre reinforcement which was the main inhibitor of the damage.

The speed of the projectile was recorded during each impact and penetration of the projectile through the concrete plate (Fig. 5). The difference of kinetic energy $\Delta E_{k}$ was determined and it was related to the thickness of the slabs $\left(\Delta E_{k} / t\right)$ and it is shown in joules per mm, further termed as $K$. Furthermore, the diameter of the projectile was considered and the parameter $\mathrm{K} / \phi$ was determined in joules per cubic centimetre (Table 2 ). 

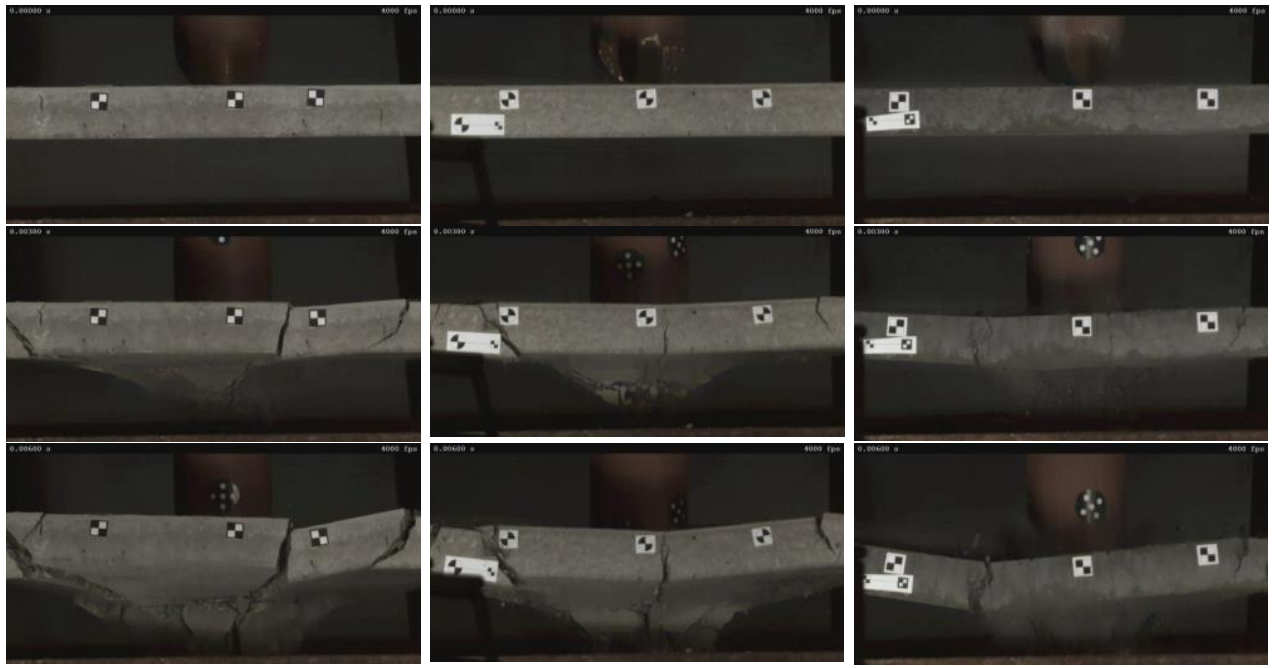

Fig. 3. View on the side of the slabs made of NSC, FRC, and HPFRC during the impact of the projectile in $3 \mathrm{~ms}$ time steps.
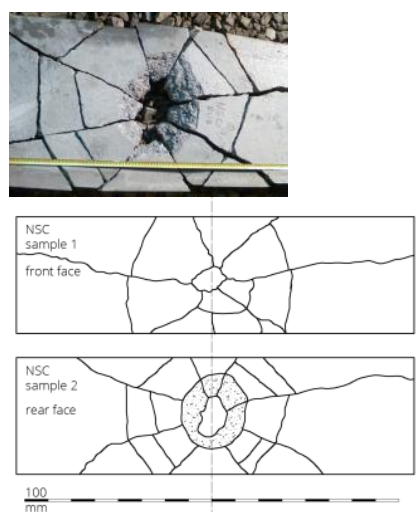
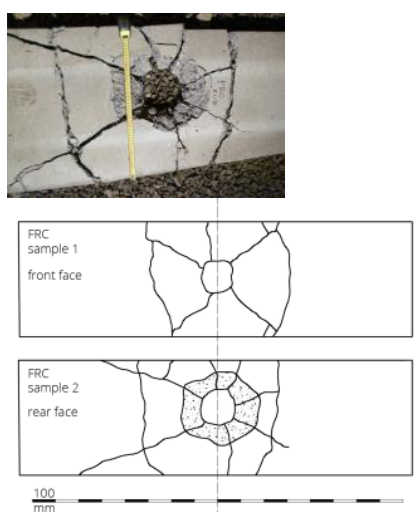
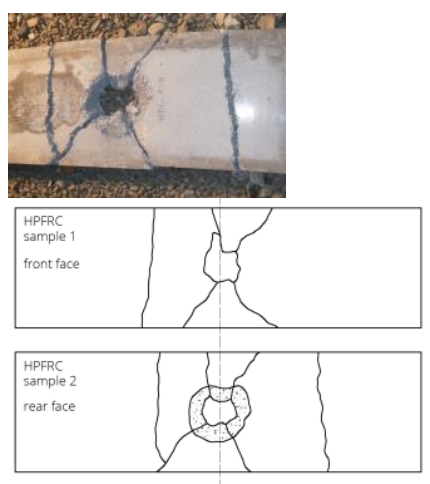

$\frac{100}{\mathrm{~mm}}-----$

Fig. 4. Photographs of the cratering damage (taken from the rear side) and schematic of the crack pattern of the NSC, FRC and HPFRC slabs from the front and rear side after the projectile impact.

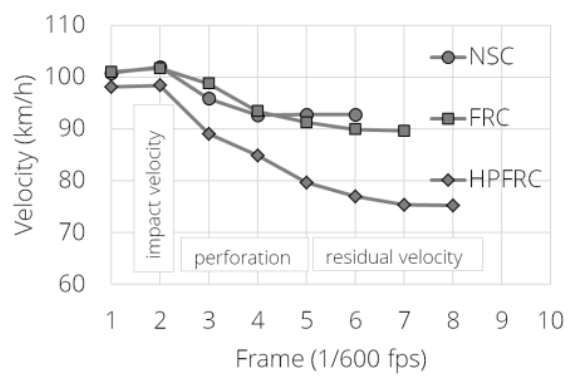

Fig. 5. Velocity of the projectile before (impact velocity) and after (residual velocity) perforation through the concrete slabs.

From the measured velocity and the calculated value of the kinetic energy $E_{k}$ of the projectile, it can be seen that the HPFRC material has the greatest ability to absorb and dissipate the 
kinetic energy of the projectile. This can be demonstrated by the value of $K$ that was determined to be $93 \mathrm{~J} / \mathrm{mm}, 114 \mathrm{~J} / \mathrm{mm}$ and $199 \mathrm{~J} / \mathrm{mm}$ for NSC, FRC and HPFRC, respectively. By including the diameter of the projectile in the calculation, the value of $K / \phi^{2}$ was determined to be $4.13 \mathrm{~J} / \mathrm{cm}^{3}, 5.07 \mathrm{~J} / \mathrm{cm}^{3}$ and $8.84 \mathrm{~J} / \mathrm{cm}^{3}$ for NSC, FRC and HPFRC, respectively (Table 2). From both calculations, it can be seen that the ability of HPFRC to dissipate the kinetic energy of the projectile is more than two times higher than that of NSC and more than 1.7 times higher compared to FRC.

Table 2. Velocity of the projectile before (impact velocity) and after (residual velocity) perforation through the concrete slabs made of NSC, FRC and HPFRC.

\begin{tabular}{|l|l|l|l|}
\hline & NSC & FRC & HPFRC \\
\hline Sample 1 - velocity before/after $(\mathrm{km} / \mathrm{h})$ & $100.6 / 91.5$ & $100.9 / 90.3$ & $99.1 / 79.30$ \\
\hline Sample 2 - velocity before/after $(\mathrm{km} / \mathrm{h})$ & $101.9 / 92.7$ & $101.7 / 89.6$ & $98.4 / 75.25$ \\
\hline Impact energy - sample 1/2 $(\mathrm{kJ})$ & $37.25 / 38.22$ & $37.47 / 38.07$ & $36.15 / 35.64$ \\
\hline$\Delta \mathrm{E}_{\mathrm{k}}-$ sample $1 / 2(\mathrm{~kJ})$ & $6.43 / 6.59$ & $7.46 / 8.52$ & $13.00 / 14.80$ \\
\hline$\Delta \mathrm{E}_{\mathrm{k}} / \mathrm{t}(\mathrm{K})$ - average $(\mathrm{J} / \mathrm{mm})$ & 93 & 114 & 199 \\
\hline $\mathrm{K} / \phi^{2}\left(\mathrm{~J} / \mathrm{cm}^{3}\right)$ & 4.13 & 5.07 & 8.84 \\
\hline
\end{tabular}

\section{Conclusions}

The study presented herein showed the results of the impact resistance of various types of concrete at the 2.8-second drop shaft and demonstrated better energy absorption and dissipation capacity of high-performance fibre-reinforced concrete compared to the conventional fibre-reinforced or normal strength concrete. Enhanced behaviour resulted mainly from dispersed reinforcement which was the main inhibitor of the damage and resulted in higher energy absorption characteristics and less crack development.

The authors gratefully acknowledge the support provided by the Faculty of Civil Engineering at the CTU in Prague and Technology Agency of the Czech Republic (project no. TP01010066). The authors would like to acknowledge the assistance given by the technical staff of the Centre of Experimental Geotechnics and by the technical staff of the Experimental Centre at CTU in Prague and by students who participated in the project (project no. SGS10/242/OHK1/3T/11).

\section{References}

1. B. Beckmann, A. Hummeltenberg, T. Weber, \& M. Curbach, Structural Engineering International, 22 (2012) 562-568.

2. D. Nicolaides, A. Kanellopoulos, M. Petrou, P. Savva, \& A. Mina, Construction and Building Materials, 95 (2015) 667-674.

3. D. Nicolaides, A. Kanellopoulos, P. Savva, \& M. Petrou, Construction and Building Materials, 95 (2015) 566-574.

4. R. Vasicek \& J. Svoboda, ICEE \& ICEER 2009 KOREA Book of Abstracts, (2009) 64-65.

5. Zezulova, E., Hasilova, K., Dvorak, P., Dubec, B., Komarkova, T-, Stoller, J. Experimental Campaign to Verify the Suitability of Ultrasound Testing Method for Steel Fiber Reinforced Concrete Fortification Structures. APPLIED SCIENCES-BASEL, 11 (18) Article Number8759, DOI 10.3390/app11188759, (2021)

6. Stoller, J. and Dvorak, P. Non-Destructive Testing of Full-Scale Slabs Before and after Blast Load, TRANSPORT MEANS - PROCEEDINGS OF THE INTERNATIONAL CONFERENCE, pp. 298-301 (2015)

7. Stoller, J. and Zezulova, E. The Field Testing of High Performance Fiber 
reinforced Concrete Slabs under the TNT Load Explosion together with the Analytical Solution and the Numerical Modelling of those Tests Results. INTERNATIONAL CONFERENCE ON MILITARY TECHNOLOGIES, pp.211-218 (2015)

8. Papán, D., Papánová, Z. Higher frequency dynamic response analysis of the foam concrete block element, MATEC Web of Conferences 196,01037 (2018) 